\title{
Repercussões Psicológicas do Adoecimento e Tratamento em Mulheres Acometidas pelo Câncer de Mama ${ }^{1}$
}

\author{
Psychological consequences of the sickening \\ and treatment of women affected by breast cancer
}

\section{Leandra Rossi}

Psicóloga graduada pela FFCLRP-USP Psicóloga do Serviço de Nefrologia Pediátrica do HC/FMRP

USP. Ex-bolsista de Iniciação Clentífica da

FAPESP.

Manoel Antônio dos Santos

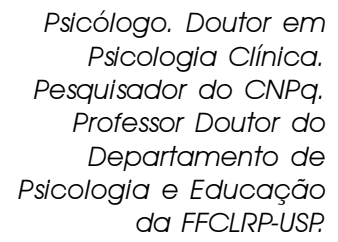

Psicólogo. Doutor em Psicologia Clínica. Pesquisador do CNPq. Professor Doutor do Departamento de Psicologia e Educação da FFCLRP-USP

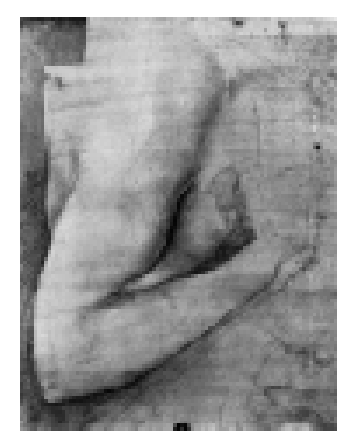

Resumo: A literatura evidencia que o diagnóstico e o tratamento do câncer de mama afetam a condição emocional da mulher. Este estudo teve como objetivo investigar as repercussões psicológicas associadas ao adoecer em mulheres com câncer de mama que foram submetidas à mastectomia (total ou parcial), radioterapia e quimioterapia. Aplicou-se uma entrevista individual semi-estruturada a 10 pacientes, com idades compreendidas entre 41 e 50 anos. Os resultados mostram que as repercussóes psicológicas variam de acordo com a fase do adoecimento e tratamento (pré-diagnóstico, diagnóstico, tratamento e pós-tratamento), afetando o ajustamento psicossocial de maneira diferente nos estágios identificados, prejudicando a qualidade de vida da mulher acometida.

Palavras-Chave: Câncer de mama, qualidade de vida, ajustamento psicossocial.

Abstract: As it is evidenced in the literature, the diagnosis and treatment of breast cancer affect the emotional condition of women. This study aimed to investigate the psychological reverberations associated to sickening in women affected by breast cancer who had already been submitted to mastectomy (total or partial), radiotherapy and chemotherapy. An individual semi-structured interview was used with 10 patients aging from 41 to 50 years old. The results show that the psychological reverberations vary according to the sickening and treatment phase (pre-diagnosis, diagnosis, treatment and post-treatment), affecting the psychosocial adjustment in different ways in the identified phases, impairing the quality of life of affected woman. Key Words: Breast cancer, quality of life, psychosocial adjustment.

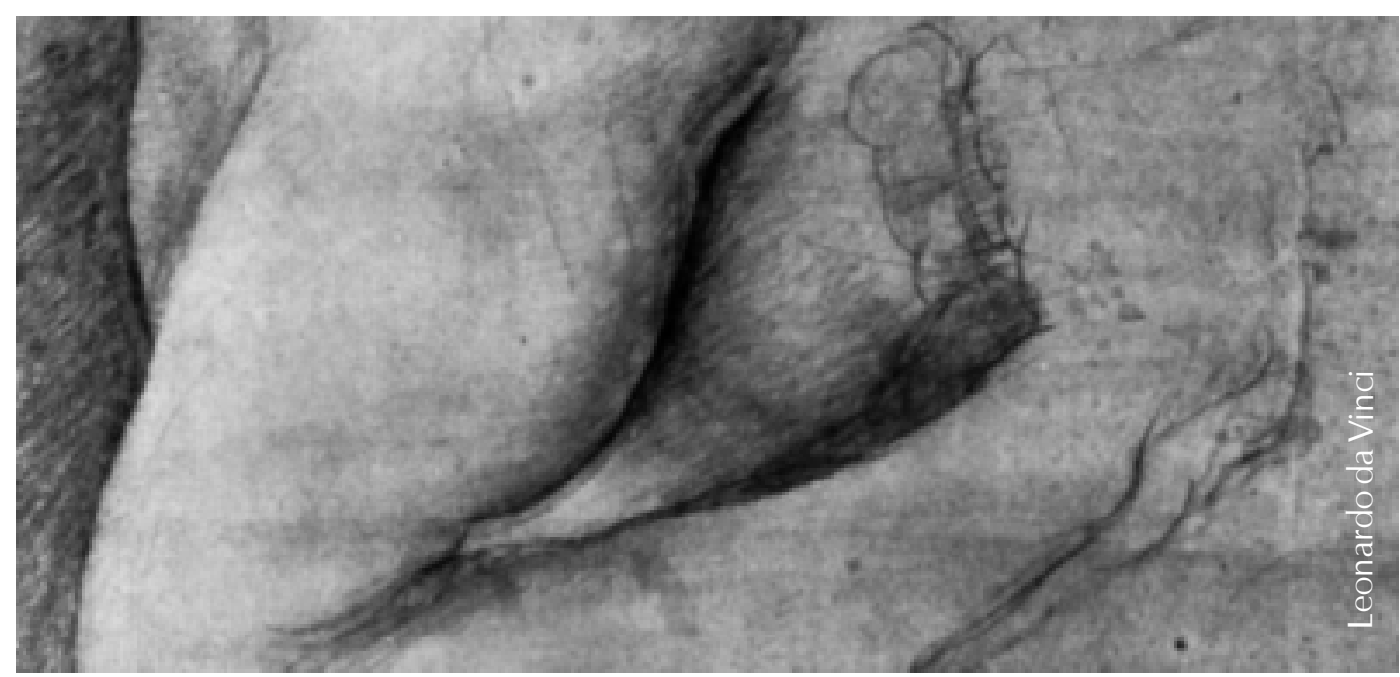

\section{O Câncer de Mama}

Ocâncer de mama representa uma das maiores causas de morteem mulheres, tanto nos países desenvolvidos quanto nos países em desenvolvimento, sendo relativamente raro antes dos 35 anos de idade (Ministério da Saúde/INCA, 1996).

Assim como outros tipos de câncer, o câncer de mama está associado a inúmeros fatores de risco, sendo os principais: o envelhecimento, história de câncer na família e menopausa tardia (após os 50 anos de idade). Devido à sua alta freqüência e pelas repercussões psicológicas que acarreta, o câncer de mama éo mais temido pelas mulheres, uma vez que afeta a percepção da sexualidade e da própria imagem corporal (Ministério da Saúde/INCA, 1996). Se detectado precocemente, por meio do auto-exame das mamas ou mamografia - procedimentos que devem ser realizados regularmente -, o câncer de mama pode ter seus efeitos atenuados, devido ao registro de tumores 
primários menores e número reduzido de linfonodos axilares invadidos pela massa tumoral.

São várias as modalidades de tratamento do câncer em seus aspectos tumorais, que incluem a cirurgia, a quimioterapia, a radioterapia, a hormonioterapia, a imunoterapia e a reabilitação. Geralmente, o tratamento do câncer requer a combinação de mais de um método terapêutico, o que aumenta a possibilidade de cura, diminui as perdas anatômicas, preserva a estética e a função dos órgãos comprometidos (Ministério da Saúde/ INCA, 1993). Essas modalidades de tratamento são bastante eficazes, uma vez que são capazes de controlar o tumor primário e suas complicações. No entanto, o planejamento terapêutico do paciente com câncer deve incluir um conjunto de cuidados, dos quais a conduta clínica e/ou cirúrgica é apenas uma parte. Assim, a "reabilitação tem como principal objetivo a melhoria da qualidade de vida do indivíduo. Deve procurar atender às necessidades específicas de cada paciente, com medidas que visem à restauração anatômica e funcional, ao suporte físico e psicológico e à paliação de sintomas" (Ministério da Saúde/INCA, 1993, s/p).

A reabilitação do paciente com câncer e o seu reajustamento social dependem, em larga medida, da formação de uma equipe multiprofissional que trabalhe de forma integrada e mantenha um relacionamento satisfatório com o paciente e seus familiares (Ministério da Saúde/INCA, 1993). O psicólogo exerce um papel fundamental junto a essa equipe, tendo em vista o atendimento das necessidades emocionais da mulher que vivencia o diagnóstico e as vicissitudes do tratamento.

\section{A Psiconcologia}

Gimenes (1994) contextualiza a Psiconcologia - interface entre a Psicologia e a Oncologia -, seu foco de estudo e níveis de intervenção (prevenção, tratamento, reabilitação e fase terminal), apresentando uma perspectiva histórica da entrada da Psicologia na área da Saúde. A autora afirma que somente nas últimas décadas diferentes abordagens psicológicas começaram a investigar as relações existentes entre personalidade, padrões comportamentais, fatores psicossociais e incidência, evolução e remissão do câncer. A realização de pesquisas nessa área reflete a preocupação com a contribuição que a Psicologia pode proporcionar na prevenção, adaptação emocional e social do indivíduo às várias etapas do tratamento oncológico, bem como na reabilitação e no manejo do paciente em fase terminal. Assim, a qualidade de vida do paciente com câncer passa a ser tão relevante quanto o seu tempo de sobrevida, o que pressupõe uma modalidade de assistência integral ao paciente e à sua família, bem como a formação de profissionais de Saúde envolvidos no atendimento dessa demanda.

Lima (1990) relata sua experiência como enfermeira do GACC (Grupo de Apoio à Criança com Câncer) do Hospital das Clínicas da Faculdade de Medicina de Ribeirão Preto. A autora nota que houve mudanças no modelo de assistência à criança com câncer, modificando o seu objeto, os instrumentos utilizados em sua prática e sua finalidade. A ênfase terapêutica foi transferida do alívio do sofrimento e prolongamento da vida para a questão da assistência à criança e sua família, tendo em vista a qualidade de vida. A autora descreve em seu trabalho como, a partir da prática, novas necessidades surgiram, tornando o modelo clínico - centrado no corpo biológico, patologia, diagnóstico e terapêutica insuficiente frente ao universo de necessidades e demandas instauradas. O objeto da assistência passa a ser o ser doente e não a doença em si; o médico passa a fazer parte de uma equipe multiprofissional, capaz de abordar o objeto em sua dimensão biopsicossocial, e a finalidade passa a ser a garantia da qualidade de vida do doente e não apenas a cura da sua doença em si, o alívio do sofrimento e o aumento da sobrevida. Essas questões, anteriormente enfatizadas pelo modelo biomédico, continuam sendo importantes, porém foram redimensionadas à luz do novo paradigma de assistência oncológica.

\section{Repercussões Psicológicas do Câncer de Mama}

O diagnóstico de câncer confronta o sujeito com a questão do imponderável, da finitude e da morte. Como toda doença potencialmente letal, traz a perda do corpo saudável, a perda da sensação de invulnerabilidade e a perda do domínio sobre a própria vida.

Kübler-Ross (1994), a partir de sua prática clínica com pacientes terminais, identificou cinco estágios caracterizados por atitudes específicas do paciente diante da morte e do morrer: (1) choque e negação: ocorrem quando o paciente toma conhecimento de que está próximo da morte e se recusa a aceitar o diagnóstico; (2) raiva: ocorre quando os pacientes se sentem frustrados, irritados ou com raiva pelo fato de estarem doentes, passando a descarregar esses sentimentos na equipe médica; (3) barganha: ocorre quando o paciente tenta negociar sua cura com a equipe médica, com os amigos e até com forças divinas, em troca de promessas e sacrifícios; (4) depressão: o paciente apresenta sinais túpicos da depressão, como desesperança, ideação suicida, retraimento, retardo psicomotor, enquanto reação aos efeitos que a doença opera sobre seu corpo ou como antecipação à possibilidade de perda real da própria vida; (5) aceitação: ocorre quando o paciente percebe que a morte é inevitável e aceita tal experiência como universal.

Parkes (1998) realizou estudos sobre as perdas na vida adulta, analisando suas repercussões psicológicas no indivíduo enlutado. Em seu livro, reuniu uma coletânea de estudos sobre as mais diversas perdas, desde a viuvez até a perda de um órgão do corpo. Esse autor considera que as reações ao luto pela morte de uma pessoa querida são semelhantes às reações a outros tipos de perda, como, por exemplo, a perda de um órgão ou uma parte do corpo. Segundo Parkes, há três aspectos importantes nas reações de luto: (1) A reação traumática, que consiste
1 Este trabalho contou com o apoio financeiro da FAPESP, sob a forma de bolsa de Iniciação Científica concedida para a primeira autora. 
em uma reação de alarme, raiva, culpa e transtorno de estresse pós-traumático, (2) a resposta de pesar, referenteà necessidade de procurar e encontrar a pessoa perdida, e (3) a transição psicossocial, caracterizada pela sensação de deslocamento entre o mundo real e o mundo idealizado, sensação de mutilação ou vazio, através da qual o indivíduo enlutado transita da negação e evitação do reconhecimento da perda para a aceitação, adotando um novo modelo interno de mundo. Em estudo realizado com homens e mulheres que se submeteram à amputação de um braço ou uma perna, o autor pôde constatar tais semelhanças. Sentimentos de ansiedade, tensão e inquietação foram comuns entre os sujeitos do estudo, bem como sentimentos de raiva e amargura. Aproximadamente $35 \%$ dos pacientes amputados admitiram sentir inveja de pessoas saudáveis. A resposta de pesar é menos óbvia em casos de perda de órgãos do corpo, mas $63 \%$ dos pacientes revelaram curiosidade e preocupações sobre o que foi feito com o órgão, após a amputação. A sensação de perda interna do self, de mutilação e de dano à integridade física é comum nos pacientes amputados.

Embora não seja um recurso utilizado em todos os casos, a cirurgia de remoção da massa tumoral é bastante freqüente, acarretando uma mutilação (parcial ou total) da mama. Esse procedimento altamente invasivo traz repercussões emocionais importantes, danificando não somente a integridade física, como também alterando a imagem psíquica que a mulher tem de si mesma e de sua sexualidade. Esse evento é acompanhado, geralmente, de vivências extremamente dolorosas relacionadas a uma sensação de perda interna do próprio self, como Parkes (1998) salienta, alterando a relação que a paciente estabelece com seu corpo e sua mente.

Wanderley (1994) afirma que o câncer de mama e o seu tratamento representam um trauma psicológico para a maioria das mulheres, já que a mama é um símbolo corpóreo da feminilidade. Segundo a autora, a mastectomia gera alterações na auto-imagem da mulher, causando sentimentos de inferioridade e medo de rejeição. Além disso, a cirurgia repercute na vida sexual da paciente, uma vez que "elas sentem-se envergonhadas, mutiladas e sexualmente repulsivas" (p. 95).

Gimenes (1988) realizou um estudo visando a compreender a influência de fatores psicossociais na sobrevida de mulheres com câncer de mama. Investigou, através de um estudo longitudinal, a existência e a natureza de possíveis relações entre fatores psicossociais e o bem-estar psicológico, bem como o papel do enfrentamento e as diversas maneiras através das quais a mulher mastectomizada lida com o estresse em diferentes fases da doença, durante o primeiro ano após a mastectomia. Entende-se por bemestar psicológico a "capacidade da mulher em estabelecer ligações afetivas, sua habilidade em manter controle emocional e comportamental e ausência de episódios apud Gimenes e Queiroz, 1997). Dentre outros resultados significativos, a pesquisadora percebeu que melhores níveis de bem-estar psicológico estão associados à facilidade de acesso aos serviços de saúdee à disponibilidadee apoio da equipe médica, o que diminui a ansiedade da mulher e melhora sua condição emocional. Outro resultado importante refere-se ao fato de as mulheres se engajarem em uma transação dinâmica com o contexto ameaçador do câncer, apresentando estratégias de enfrentamento particulares que respondem às exigências de cada fase da doença.

A autora aponta para a necessidade de intervenção em vários níveis, tendo em vista o bem-estar psicológico dessa clientela específica: (1) elaborar programas de intervenção psicossocial com ênfase na aquisição de habilidades de enfrentamento específicas para cada contexto do tratamento do câncer de mama; (2) preparar profissionais de saúde envolvidos como cuidado específico de mulheres mastectomizadas, no sentido de trabalhar as angústias das mesmas, bem como de conscientizá-los das estratégias de enfrentamento utilizadas pelas pacientes; (3) preparar os profissionais de saúde para lidar com as distintas reações emocionais apresentadas pelas pacientes nas diferentes fases do tratamento; (4) proporcionar apoio psicológico aos familiares.

\section{Objetivos}

O objetivo geral do presente estudo foi investigar as repercussões psicológicas associadas ao adoecer em mulheres com câncer de mama que já foram submetidas à mastectomia (total ou parcial), radioterapia e quimioterapia.

Como objetivo específico, buscou-se identificar suas vivências em diferentes estágios do tratamento: diagnóstico do câncer, o tratamento (mastectomia total ou parcial, tratamento radioterápico e quimioterápico) e a reabilitação (pós-tratamento).

\section{Método}

\section{Participantes}

A amostra foi composta por dez mulheres com diagnóstico de câncer de mama, com idade compreendida entre 41 e 50 anos, que já haviam sido submetidas à mastectomia (total ou parcial), radioterapia e quimioterapia. Eram pacientes de um centro especializado em assistência oncológica vinculado a um hospital beneficente, localizado em centro urbano de uma cidade do interior do Estado de São Paulo, ou indicadas por estas. As participantes foram avaliadas de fevereiro a agosto de 2001.

Os dados sociodemográficos das participantes aparecem sistematizados na Tabela 1. As participantes foram relacionadas por ordem de adesão ao estudo. Visando a preservar a identidade das participantes, os nomes utilizados são fictícios. 
Tabela 1 - Perfil sociodemográfico, educacional e ocupacional das participantes do estudo.

\begin{tabular}{|c|c|c|c|c|c|c|}
\hline Participante & Idade & Estado Civil & Religião & Escolaridade & Trabalho atual & Filhos \\
\hline Laura & 42 & Casada & Católica & Superior completo & Secretária & 1 (adotada) \\
\hline Rita & 44 & Casada & Católica & $\begin{array}{l}\text { Concluiu } \\
\text { a } 4^{\text {a }} \text { série do } 1^{\circ} \text { grau }\end{array}$ & $\begin{array}{l}\text { Desempregada- } \\
\text { Do lar }\end{array}$ & 2 \\
\hline Silvana & 44 & Desquitada & Católica & Superior completo & Dona de lanchonete & 2 \\
\hline Luíza & 41 & Casada & Católica & $\begin{array}{l}\text { Concluiu a } 3^{a^{\circ}} \text { série } \\
\text { do } 1^{\circ} \text { grau }\end{array}$ & Afastada-Doméstica & 1 \\
\hline Joana & 43 & Casada & Evangélica & $\begin{array}{l}\text { Concluiu a } 4^{\text {a }} \text { série } \\
\text { do } 1^{\circ} \text { grau }\end{array}$ & Desempregada & 1 \\
\hline Helena & 46 & Casada & Não tem & $\begin{array}{l}\text { Segundo grau } \\
\text { completo }\end{array}$ & $\begin{array}{l}\text { cabeleireira3 } \\
\text { Afastada }\end{array}$ & \\
\hline Eliana & 50 & Casada & Católica & Superior completo & Afastada-bancária & 2 \\
\hline Heloísa & 47 & Casada & Católica & Superior completo & Aposentada & 2 \\
\hline Márcia & 42 & Casada & Católica & $\begin{array}{l}\text { Segundo grau } \\
\text { completo }\end{array}$ & Do lar & 2 \\
\hline Rose & 46 & Desquitada & Cristã & $\begin{array}{l}\text { Concluiu a } 4^{\text {a }} \text { série } \\
\text { do } 1^{\circ} \text { grau }\end{array}$ & Doméstica & 2 \\
\hline
\end{tabular}

As características clínicas das participantes do estudo aparecem sistematizadas na Tabela 2.

Tabela 2: Perfil clínico das participantes do estudo.

\begin{tabular}{|c|c|c|c|c|}
\hline Participante & Data do diagnóstico & Cirurgia & Procedimentos & Casos de câncer na família \\
\hline Laura & Setembro-1999 & Parcial & Cirurgia, Rádio eQuimioterapia & 2 casos (mama e útero) \\
\hline Rita & Março - 199 & Parcial & Cirurgia, Rádio e Quimioterapia & 1 caso (língua) \\
\hline Silvana & Janeiro - 2000 & Radical & Cirurgia, Rádio e Quimioterapia & 1 caso (pele) \\
\hline Luíza & Maio-2000 & Radical & $\begin{array}{l}\text { Quimioterapia, Rádio, } \\
\text { Cirurgia e Quimioterapia }\end{array}$ & 2 casos (próstata e mama) \\
\hline Joana & Março-1999 & Radical & Cirurgia, Rádio e Quimioterapia & 2 casos (mama) \\
\hline Helena & Maio-2000 & Radical & $\begin{array}{l}\text { Quimioterapia, Rádio, } \\
\text { Cirurgia e Quimioterapia }\end{array}$ & 2 casos (ossos e ovário) \\
\hline Eliana & Janeiro-1999 & Radical & Cirurgia, Quimioterapia e Rádio & 1 caso (mama) \\
\hline Heloísa & Junho-2000 & Parcial & Cirurgia, Quimioterapia e Rádio & 2 casos (mama e próstata) \\
\hline Márcia & Julho-1998 & Radical & Cirurgia, Rádio e Quimioterapia & 1 caso (leucemia) \\
\hline Rose & Fevereiro - 1998 & Radical & $\begin{array}{l}\text { Quimioterapia, Rádio, } \\
\text { Cirurgia e Quimioterapia }\end{array}$ & Suspeita de 1 caso (intestino) \\
\hline
\end{tabular}

\section{Critérios para inclusão na amostra}

Os critérios de inclusão na amostra foram os seguintes:

o sexo: foram inclúdas na amostra apenas pacientes do sexo feminino.

1] a idade: foram incluídas na amostra pacientes com faixa etária entre 41 e 50 anos $^{2}$.

$\square$ o diagnóstico: foram incluídas na amostra apenas pacientes com diagnóstico de câncer de mama.

$\square$ o tempo de doença (data do diagnóstico): foram incluídas na amostra pacientes que receberam o diagnóstico nos anos de 1998,1999 e $2000^{3}$.

$\square$ acessibilidade: as participantes deveriam estar em seguimento médico junto ao centro especializado de assistência oncológica.
No decorrer da coleta de dados, decidiu-seampliar o critério de acessibilidade, incluindo-se duas pacientes que haviam feito seguimento médico em outras instituições hospitalares da mesma cidade.

7 fase do tratamento: foram incluídas na amostra apenas as pacientes que já haviam se submetido à mastectomia (total ou parcial) e que já haviam passado por tratamento radioterápico equimioterápico.

\section{Instrumento: entrevista semi-estruturada}

As entrevistas visaram à coleta dos dados relativos à história pessoal e familiar dos sujeitos, bem como do processo de adoecimento, desde o aparecimento dos sintomas e confirmação do diagnóstico até o tratamento, em seus
2 Na ocasião da elaboração do projeto, foram feitos levantamentos junto aos arquivos da instituição hospitalar onde seria realizada a coleta de dados e foram obtidas listas de pacientes com faixas etárias variadas, sendo que a lista de 41 a 50 anos oferecia o maior número de pacientes, levando-se em conta os demais critérios de inclusão na amostra.

3 Inicialmente, comporiam a amostra apenas pacientes que 
diferentes estágios, finalizando com as perspectivas de vida e planos para o futuro.

\section{Procedimento de coleta de dados}

Inicialmente, foi realizado um estudo-piloto, para que o instrumento utilizado e o procedimento de coleta de dados fossem testados e avaliados junto à população-alvo da presente investigação e, a partir disso, fosse definida a forma definitiva de aplicação.

Em todas as situações, a entrevista foi aplicada individualmente, em situação face a face, em um ambiente preservado (sala do centro especializado ou na residência da paciente, caso preferisse), com condições adequadas de conforto.

Depois de definida a forma definitiva de aplicação do roteiro deentrevista, o próximo passo foi o contato com as pacientes que correspondiam aos critérios de inclusão na amostra. As pacientes foram contatadas por telefone e uma conversa inicial foi necessária para que fossem explicitados os objetivos e as condições de realização do estudo. Nesse primeiro contato telefônico, a pesquisadora oferecia às pacientes a possibilidade de um encontro para que fossem proporcionados maiores esclarecimentos sobre a realização da pesquisa, a fim de fornecer-lhes subsídios que fundamentassem a decisão de participar ou não do estudo. Assim, as participantes contatadas que se mostraram disponíveis para comparecerem a esse primeiro encontro tiveram a oportunidade de serem esclarecidas da maneira mais ampla e completa possível sobre os objetivos e limites do estudo, e os prováveis benefícios e riscos envolvidos na pesquisa, através de um rapport que se propunha a oferecer ativamente informações que pudessem fundamentar a tomada de decisão sobre a conveniência, para as mulheres contatadas, de submeterem-se ou não aos procedimentos da pesquisa naquela etapa de suas vidas.

Observou-se que esse primeiro encontro, em todos os casos, já se constituiu como o início da coleta de dados, dado que, após a leitura do Termo de Consentimento Livre e Esclarecido, todas as pacientes que haviam atendido à convocação da pesquisadora e comparecido ao hospital já se colocaram à disposição para iniciar a entrevista. $\mathrm{O}$ consentimento foi formalizado mediante a assinatura do Termo de Consentimento.

O número de encontros com as pacientes variou de dois a três, devido à variação de disponibilidade de tempo e ao ritmo próprio de cada uma. Procurou-se estabelecer um vínculo favorável entre pesquisadora e participantes, de modo que estas pudessem se sentirà vontade para explicitar possíveis mobilizações emocionais (reações de ansiedade, por exemplo) ou variações de motivação. Assim, a duração e o número de encontros foi variável (de um a três), tendo em vista o respeito às condições emocionais e motivacionais das participantes.

Terminada a aplicação dos instrumentos com as participantes, as entrevistas audiogravadas foram transcritas literalmente e na íntegra.

\section{Procedimento de tratamento dos dados}

As entrevistas foram transcritas e em sua análise foi utilizada uma abordagem qualitativa, visando a identificar as concepções, crenças, valores, motivações e atitudes das participantes. O método empregado foi a análise de conteúdo temática (Triviños, 1992; Minayo, 1994). São três as etapas desse processo de análise: pré-análise (organização do material e sistematização das idéias); descrição analítica (categorização dos dados em unidades de registros) e interpretação referencial (tratamento dos dados e interpretações).

Assim, uma vez identificados os temas principais, procedeuse à classificação dos segmentos de falas de acordo com as unidades temáticas. Em seguida, foi realizada a interpretação dos resultados dessa análise, buscando-se apreender o modo como as pacientes vivenciam e se organizam frente à situação do câncer de mama e seu tratamento.

\section{Aspectos Éticos}

Alguns cuidados éticos foram adotados para a inclusão dos sujeitos no presente estudo. Em primeiro lugar, teve-se como princípio básico o respeito às voluntárias eà instituição hospitalar. Assim, o projeto foi encaminhado para o Comitê de Ética em Pesquisa da FFCLRP-USP, tendo sido aprovado. Como parte dos pré-requisitos estipulados por esse Comitê para a análise do projeto, constavam as assinaturas do diretorclínico da instituição hospitalar e do responsável pelo Departamento de Psicologia e Educação da FFCLRP-USP afirmando estarem cientes e de acordo com a realização da coleta de dados.

Tomou-se o cuidado de esclarecer antecipadamente os objetivos do trabalho e as condições de sigilo profissional para cada participante, sendo que a pesquisa só foi realizada comaquelas que concordaram abertamente com otrabalho e assinaramo Termo de Consentimento Livree Esclarecido. Foi também explicitado que a não aceitação de participação no trabalho não traria nenhum prejuízo ao atendimento institucional da paciente.

\section{Resultados e Discussão}

O material coligido por meio das entrevistas evidenciou que as vivências psicológicas relatadas pelas pacientes organizam-se em torno de diferentes momentos, demarcados em função da etapa do tratamento. Foi possível, assim, identificar quatro momentos fundamentais vivenciados pelas participantes do estudo, desde o aparecimento dos primeiros sintomas do câncer de mama até a finalização do tratamento e o início do processo de reabilitação. As repercussões psicológicas relatadas são peculiares a cada um desses momentos, a saber: momento pré-diagnóstico, etapa do diagnóstico, etapa do tratamento e momento pós-tratamento.

O momento pré-diagnóstico antecede à confirmação do diagnóstico; não diz respeito apenas ao momento de suspeita de que algo não vai bem com o próprio corpo, mas abrange também o tipo de relação 
estabelecida por essas mulheres com o próprio corpo antes do adoecimento. Algumas pacientes se remetem a essa fase da vida relembrando a maneira como lidavam como binômio saúde-doença, admitindo um certo descuido com relação ao próprio corpo, traduzido em hábitos alimentares pouco saudáveis e dependência química (sobretudo tabagismo).

A fala de Laura exemplifica essa questão da negligência como auto-cuidado:

"...eu tive gastrite, eu fumava, não ligava muito, sabe? Comia carne, ah, não comia verdura, sabe quando você não liga muito? Não era muito relaxada não, mas não ia muito ao médico, aquela coisa de fazer Papanicolau todo ano, aquela coisa certinha, né? Eu ia quando precisava, aídemorava três ou quatro anos. Que eu játive antecedentes que eu teria que ter cuidado com mais... mais atenção, no caso da mama..." (Laura, 42 anos).

Segundo o Ministério da Saúde (1996), as causas do câncer podem ser externas (meio-ambiente, costumes e hábitos próprios de uma sociedade ou cultura) ou internas (predisposição genética) e, na maioria das vezes, elas estão inter-relacionadas. Assim, a formação de tumores e neoplasias malignas depende da combinação de inúmeros fatores causais. O que sabemos, no estágio atual do conhecimento, é que o câncer é uma doença de etiologia multicausal.

Conforme aponta o Ministério da Saúde/INCA (1996), o câncer de mama está associado a três principais fatores de risco - envelhecimento, história de câncer na família e menopausa tardia (após 50 anos) - dentre outros fatores, considerados secundários. Os resultados apontam que a maioria das participantes do presente estudo (9) se refere a história de câncer na família (Tabela 2), sendo que cinco participantes relatam pelo menos um caso de câncer entre os antecedentes familiares. Esse achado corrobora o apontamento encontrado em inúmeras pesquisas na área oncológica de que a predisposição genética constitui um fator de risco importante para a etiologia do câncer.

Um outro aspecto que merece destaque nesse momento pré-diagnóstico diz respeito à postergação da consulta médica, praticada por seis participantes do estudo, eque pode ser exemplificada na fala de Helena:

"Mas, desse ínterim, eu fiquei um ano sem ir, aí comeceia sentir que tinha um nódulo no seio, né, que tava retraindo o mamilo..." (Helena, 46 anos).

Os resultados indicam que a falta de acesso aos serviços de assistência médica não aparece como único impedimento para que essas mulheres procurem ajuda profissional. As participantes deste estudo, que contavam com antecedentes familiares importantes (história de câncer na família), embora tivessem acesso a esse tipo de assistência, não procuraram por ele. Algumas até passaram por consultas ginecológicas de rotina, quando foram identificados problemas que mereciam atenção sistemática, como por exemplo displasia mamária, microcalcificações e nódulos, mas não deram seguimento às recomendações médicas no sentido de realizar exames complementares e acompanhamento regular. A postergação da consulta médica parece ser uma atitude tomada por essas mulheres ao entrar em contato com a possibilidade de estar com câncer de mama. Os antecedentes familiares e os primeiros sintomas sugestivos de possíveis problemas posteriores na mama aparecem a essas mulheres como dados de realidade que por si só precisam ser negados, pois antecipam o estigma associado ao câncer de mama, e isso parece se dar bem antes de a neoplasia ser diagnosticada. Assim, pode-se inferir que o contato com a possibilidade de vir a desenvolver uma neoplasia mamária é sentida como uma realidade extremamente dolorosa eameaçadora, que suscita atitudes de evitação e distanciamento como forma de se evitar o sofrimento psíquico resultante. Écomo se elas procurassem "não pensar" sobre o assunto, acreditando estarem, assim, a salvo das inquietações e emoções geradas pela aceitação da possibilidade de um dia se verem afetadas pela enfermidade. Essa evitação é tão intensa que assume um caráter de autêntica negação da realidade por parte dessas mulheres, que se observa antes mesmo que a realidade temida seja objetivada e confirmada pelos laudos diagnósticos.

Percebe-se, assim, que o estágio de choque e negação, proposto por Kübler-Ross (1994), que acontece quando o paciente toma conhecimento de queestá próximo da morte e se recusa a aceitar o diagnóstico, pode ser antecipado, compreendendo o momento em que os primeiros sintomas de uma possível patologia começam a aparecer-o momento pré-diagnóstico. Observamos que as mulheres do presente estudo ignoraram sistematicamente uma série de indícios, que freqüentemente são enfatizados pelas campanhas de saúde que visam o esclarecimento da opinião pública sobre os riscos e sinais precursores do câncer de mama. Esse aspecto pode ser ilustrado pela fala de Joana:

“...eu não queria acreditar, sabe? Porque eu passava a mão assim e sentia, eu achava que tinha um caroço, e ao mesmo tempo, eu falava não tem não, issoécoisa da minha cabeça'..." (Joana, 43 anos).

No depoimento das pacientes, é bastante evidente o papel desempenhado pelo estigma associado ao câncer de mama. Conforme consta no documento do Ministério da Saúde/INCA (1996), é o tipo de câncer mais temido pelas mulheres e, por afetar a percepção da sexualidade e da própria imagem corporal, o estigma associado à doença sobrepõe-se muitas vezes à conscientização dos riscos, que se potencializam quando o tumor não é detectado precocemente. Os dados obtidos na presente investigação corroboram, assim, o achado de outros estudos da literatura, que mostram que o componente intelectual, bastante explorado pelas campanhas de prevenção de neoplasias malignas, é necessário e precisa ser valorizado, mas não é suficiente para que se garanta a prevenção primária do câncer de mama.

Aetapa do diagnósticoéo momento emqueas mulheres entram em contato com a situação objetiva e concreta de estar com câncer de mama, após a comunicação formal do "...eutive gastrite, eu fumava, não ligova muito, sabe? Comia carne, ah, não comia verdura, sabe quando você não liga muito? Não era muito relaxada não, mas não ia muito ao médico, aquela coisa de fazer Papanicolau todo ano, aquela coisa certinha, né? Eu ia quando precisova, aí demorava três ou quatro anos. Que eu já tive antecedentes que eu teria que ter cuidado com mais... mais atenção, no caso da mama..."

Laura, 42 anos 
diagnóstico pelo profissional médico. Em consonância com o momento pré-diagnóstico, em que as participantes relatam que já haviam estabelecido um primeiro contato com a possibilidade de estar com câncer de mama, nesse segundo momento elas afirmam que pressentiram o diagnóstico antes mesmo que fosse confirmado pelos laudos médicos.

Segundo Parkes (1998), a reação traumática é uma das primeiras fases constituintes das reações de luto pela morte de uma pessoa querida ou pela perda de um órgão do corpo. A reação traumática consiste em uma reação de alarme, raiva, culpa e transtorno de estresse pós-traumático. A reação de alarme se assemelha ao choque e ao impacto vivenciado pelas participantes deste estudo ao se depararem com a realidade que thes foi imposta pela situação do diagnóstico. Tal reação pode ser exemplificada pela fala de Márcia:

"O câncer, quando eu soube, sabe, é uma coisa muito forte, o câncer é uma palavra muito forte... Foi como se tivesse uma linha, e você estivesse em cima dessa linha, que você ia cair. Desse jeito, é desesperador, é uma bomba em cima de você" (Márcia, 42 anos).

"O câncer, quando eu soube, sabe, é uma coisa muito forte, o câncer é uma palowra muito forte... Foi como setivesse uma linha, evocê estivesse em cima dessa linha, que você ia cair. Desse jeito, é desesperador, é uma bomba em cima de você"

Márcia, 42 anos
Assim como o forte impacto emocional vivenciado diante da situação do diagnóstico, o vislumbre da morte é um outro aspecto muito evidente nos resultados do presente estudo. Ocontato coma realidade de estar com uma doença grave - o câncer de mama - fez aflorar na maioria das participantes deste estudo a consciência da possibilidade de morte iminente. $\mathrm{O}$ vislumbre da morte pode ser exemplificado pela fala de Silvana:

"...de vez em quando me dava uns cinco minutos assim: 'meu Deus, eu vou morrer, eu vou pra debaixo da terra, como é que vai fazer?'"'(Silvana, 44 anos).

Os trabalhos da área de Psiconcologia salientam o aparecimento de pensamentos intrusivos como uma ocorrência comum nesses pacientes. Além de corroborar esses achados, percebemos que o vislumbre da morte trouxe às mulheres investigadas a experiência de diversos outros sentimentos disfóricos, tais como tristeza, insegurança temor relacionado ao futuro e ao desconhecido (receio do tratamento que iriam enfrentar e as incertezas ligadas às possibilidades decura, acrescidas da perspectiva de conviver com a mutilação e suas repercussões sobre a vida sexual e o relacionamento conjugal). Além disso, percebemos que o receio de um possível desamparo dos filhos era uma sombra que pairava onipresentemente na vida emocional dessas mulheres.

Contrapondo-se a todos esses sentimentos negativos despertados pela comunicação do diagnóstico, essas mulheres manifestaram muitas expectativas de cura e muita esperança com relação ao sucesso dos procedimentos terapêuticos que ainda estavam por vir. Nesse momento, configura-se um impasse: reforçar a esperança de que se pode obter um resultado favorável com o tratamento ou entregar-se a sentimentos de impotência e desespero. Os participantes optaram por se "agarrar à vida", mantendo

acesa a centelha da esperança na possibilidade de cura. Essa estratégia de enfrentamento é extremamente importante para a manutenção da auto-estima e do nível de motivação para o engajamento no tratamento, o que pôde ser observado na aderência aos procedimentos que se seguiram.

Os resultados indicam, ainda, que a fase de comunicação do diagnósticoé um momento de fundamental importância para que seja estabelecida uma relação de confiança entre o profissional médico e a paciente. Os achados do presente estudo evidenciam que há uma forte associação entre a postura de acolhimento por parte do profissional médico e o grau de satisfação do paciente com relação à forma como o diagnóstico foi comunicado. Notamosque o acolhimento percebido variou desde um extremo positivo até o negativo. Esses dois pólos são exemplificados logo abaixo pelas falas de Joana - satisfeita com a forma como o diagnóstico foi comunicado-ede Márcia-insatisfeita com a forma como o diagnóstico foi transmitido:

"Ele me acolheu bastante... (...) ...ele tem o maior carinho, sabe? Eleé... pra mim eleéuma pessoa excelente, ele me deu muita força..." (Joana, 43 anos).

"Ele não me comunicou, ele me jogou o exame em cima da mesa e me mandou aguardar um pouquinho e ficou meia hora lá fora... (...) Ele nem procurou ver se eu tava viva ou morta..." (Márcia, 42 anos).

Para dar seguimento ao tratamento, Joana optou por continuar com o mesmo médico, enquanto Márcia procurou outro profissional para dar início ao seu tratamento. Esses dados mostram que a qualidade da relação médico-paciente parece ser crucial para o desfecho do tratamento. Esses resultados estão em concordância com os resultados de uma investigação realizada por Gimenes (1988). Em um estudo longitudinal, que visava a compreender a natureza das possíveis relações entre fatores psicossociais e bem-estar psicológico em mulheres mastectomizadas, Gimenes (1988) concluiu que a disponibilidade e o apoio da equipe médica diminuem essencialmente a ansiedade da mulher, melhorando sua condição emocional e seu bem-estar psicológico. A autora aponta para a necessidade de preparar profissionais de saúde envolvidos com o cuidado específico dessa clientela, no sentido de trabalhar as angústias das mesmas, capacitando-os a lidarem com as distintas reações emocionais apresentadas pelas pacientes nas diferentes fases do tratamento.

Um outro aspecto levantado pelo presente estudo diz respeito à conduta médica. As participantes alegam terem sido vítimas de negligência médica. Omissão de conduta, erros diagnósticos e esclarecimentos insuficientes acerca do tratamento eseus efeitos foram as queixas mais freqüentes das mulheres entrevistadas, que são ilustradas pelas falas abaixo:

"Ninguém sabia que era câncer, um falava que era alergia de sutiã, outro de sabonete, outro alergia de aranha, micose, cada um falava que era um departamento diferente... (...) Eu falava: 'gente, eu não agüento, eu tenho uma coleção de pomadas em casa, vocês têm obrigação de descobrir isso daqui, tem que sarar'..." (Silvana, 44 anos). 
"Ele não me pediu exame nem nada..." (Luíza, 41 anos).

"...eles falaram que a quimioterapia seria pra não deixar ele crescer, e que a rádio ia fazer ele diminuir e talvez, se ele fosse menor, nem precisasse fazer uma cirurgia, mas como ele não diminuiu tanto assim... Mas foi... porque ele soltou o bico do seio, mas pra mim isso não cheirou nem fedeu, porque logo depois eu já fiz a cirurgia, então o quê que adianta ele diminuir, soltar o bico, se eu não ia permanecer com a mama? Então eu não vejo benefícios, já que a cirurgia teve que ser radical mesmo. Já que teria que ser, fizesse ela de uma vez, pra quê passar pelo transtorno da quimioterapia, de vocêter que ir lá todos os dias fazer a rádio, se já tava certo que seria uma cirurgia radical?" (Helena, 46 anos).

A fala de Helena ilustra os efeitos desastrosos da falta de informação acerca das características da doença e das finalidades do tratamento, que poderiam ser melhor esclarecidas pelo profissional médico. Esses dados sugerem que parece haver uma falta de preparo do profissional médico para lidar com uma especialidade de alta complexidade como a oncologia, cujas patologias exigem da equipe cuidadora um dimensionamento mais amplo acerca da doença e de suas repercussões no plano biopsicossocial.

Na etapa do tratamento, vários aspectos merecem consideração. Os resultados mostram que a decisão pelo tratamento não é construída pelo médico e o paciente de forma compartilhada e dialogada. Ao contrário, o tratamento é imposto pelo profissional médico como única opção, alienando a paciente de uma decisão que deveria ser sua e de sua família. A linguagem utilizada pelo médico não oferece espaço para que a paciente expresse suas discordâncias e coloqueà prova as recomendações (sentidas muitas vezes como imposições) do profissional. Os depoimentos denotam uma atitude de marcada passividade frente à autoridade médica. Éo que se pode perceber nas falas de Rita e Heló́sa:

"Eu não queria, mas ele falou que tinha que fazer..." (Rita, 44 anos).

"Eu não decidi muito não, decidiram, né? Falaram que tinha que fazer e eu aceitei na hora, também não tinha nem... já tinham marcado até hospital, marcado médico já pra me operar daí dois dias, então..." (Heloísa, 47 anos).

Chama a atenção o fato de que não é dada à paciente a oportunidade de ser ouvida ou de posicionar-se pessoalmente em relação à cirurgia. A postura médica é apontada por essas mulheres como inflexível, já que o profissional lhes parece pouco atento ao impacto subjetivo causado pela comunicação do diagnóstico, que nos casos analisados foi feita junto à indicação terapêutica (cirurgia na maioria das vezes, ou radioterapia e quimioterapia antecedendo a cirurgia). Sendo assim, não é aberto um espaço de diálogo para que a paciente possa elaborar psicologicamente o evento do diagnóstico. A paciente, por sua vez, não se sente à vontade para contestar aspectos da decisão sobre o tratamento que lhe é comunicada de maneira imperativa, ou mesmo a decisão em si, já que a intervenção cirúrgica the aparece quase como um fato consumado. Outro aspecto relevante, ao nosso ver, é que não se encontra nas falas qualquer menção ao papel do marido ou de algum outro familiar durante a construção da decisão sobre a cirurgia. As entrevistadas mencionam que receberam apoio familiar, tanto do marido/parceiro como da família de origem, apenas depois de estabelecida a decisão pela cirurgia.

Ainda no que concerneà etapa do tratamento, as queixas na maioria das vezes estão relacionadas com os efeitos físicos combinados da radioterapia, quimioterapia e cirurgia. As participantes citam sensações de desconforto com relação à estética e queda de cabelos. É evidente que a percepção da degradação física decorrente dos procedimentos terapêuticos afeta a imagem corporal. Isso pode ser ilustrado pela fala de Silvana:

"Depois que eu fiz a cirurgia, eu acho que nunca mais vai ser igual. Eu falo que esse tipo de cirurgia, mais a radioterapia, mais a quimioterapia, muda seu RG, muda por completo..." (Silvana, 44 anos).

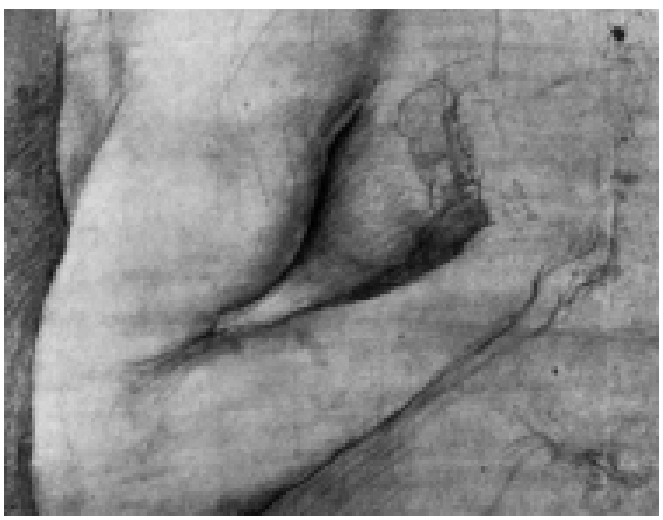

"Depois que eu fiz a cirurgia, eu acho que nunca mais vai ser igual. Eu falo que esse tipo de cirurgia, mais a radioterapia, mais a quimioterapia muda seu RG, muda por completo..."

Silvana 44 anos

Apesar do forte impacto psicológico, nove participantes fizeram uma avaliação positiva do tratamento ao qual foram submetidas. A possibilidade de cura e a prevenção da recidiva foram os principais argumentos utilizados pelas participantes deste estudo para justificarem a correção do tratamento realizado. Mesmo assim, as participantes não deixaram de reconhecer os danos e prejuízos colaterais que esse mesmo tratamento - que pode contribuir para curar e prevenir - pode acarretar ao organismo. Elas se queixam dos efeitos adversos: os enjôos, as queimaduras na pele decorrentes da radioterapia, a queda do rendimento funcional, dentre outros. A quimioterapia foi considerada pela maioria das participantes como o pior procedimento pelo qual passaram, enquanto a radioterapia foi considerada a modalidade mais fácil de ser realizada e enfrentada.

No momento pós-tratamento, aparecem as repercussões psicológicas que afetam o plano do relacionamento afetivosexual. Os resultados mostram que as mulheres que dispunham de um relacionamento afetivo sólido não sofreram significativas alterações na vida sexual após a doença e o tratamento, enquanto aquelas quejá vivenciavam insatisfação conjugal anterior à doença sofreram drásticas 
alterações na vida sexual (vida sexual inativa). Algumas participantes quejá não mantinham relacionamento afetivosexual antes da doença passaram a se afastar do sexo oposto. Esse aumento do distanciamento foi justificado como uma postura de descrença com relação a novos relacionamentos, temendo frustrar o parceiro e, sobretudo, sofrer rejeição pela condição de "mutiladas". Aquelas que não haviam recuperado o padrão anterior de relacionamento sexual após a doença etratamento manifestaram curiosidade sobre como o parceiro reagiria, se ele aceitaria ou não a falta do seio.

Esses dados estão em concordância com os apontamentos trazidos por Wanderley (1994), que afirma representarem o câncer de mama e seu tratamento um trauma psicológico para a maioria das mulheres, já que a mama é um símbolo corpóreo da sensualidade feminina. A referida autora aponta ainda para o fato de a mastectomia poder acarretar sentimentos de inferioridade e mutilação, medo de rejeição evergonha. Independentemente do grau deatividade sexual das participantes do presente estudo, a maior parte daquelas quevoltaram a manter relacionamento sexual após a doença e tratamento referem-se a mudanças na maneira de se comportar durante o ato sexual, adotando um comportamento de esconder o seio ou experimentando vergonha ou repulsa pelo parceiro. Esse achado é bastante significativo e revelador do quanto a vida afetiva das mulheres mastectomizadas é afetada pela extirpação da mama.

Terminado todo o tratamento, essas mulheres, já em fase de reabilitação, avaliam a experiência de ter tido câncer de mama e de ter passado por um tratamento doloroso, visualizando as mudanças negativas e positivas em suas vidas. O sentimento de mutilação e a sensação de não ser mais a mesma pessoa aparecem como mudanças negativas. Em contraponto a todas as repercussões psicológicas negativas desencadeadas pelo câncer de mama, muitos aspectos positivos da experiência que essas mulheres vivenciaram são levantados e considerados. Elas afirmaram terem passado a valorizar mais a natureza - aqui representando tudo o que pulsa e está vivo -, o momento presente e a vida de um modo geral. Parece que a situação de estar com câncer de mama, uma doença grave, que exigiu um tratamento doloroso e que trouxe para bem perto delas a possibilidade da morte, proporcionou-lhes, por outro lado, um redimensionamento da vida e uma revisão dos valores. O reconhecimento de aspectos positivos em uma experiência tão dolorosa como o câncer de mama e seu tratamento mostra a existência de bons recursos adaptativos e de enfrentamento nessas mulheres, que se sentem aliviadas após vivenciarem o "sufoco". Para ilustrar essa questão, podemos recorrer às palavras de Eliana:

"...de viver bem, de aproveitar a vida que eu ganhei depois de todo esse sufoco, né? Realmente aproveitar a vida, porque ela quase foi embora, né, ela quase foi pro ralo, então eu quero aproveitar o que restou da minha vida, praticamente é como se eu tivesse nascido de novo, então parece que eu quero começar a viver, tem ainda muita coisa que eu quero fazer, né? É como se eu tivesse assim fazendo planos, como se eu fosse uma adolescente fazendo planos pro futuro, é como se eu tivesse que pensar ainda em quanta coisa eu vou ter pela frente, quantos sonhos eu ainda posso ter, né?" (Eliana, 50 anos).
Finalizando, pode-se dizer que os objetivos a que nos propusemos alcançar como presenteestudo foramatingidos. Pudemos apreender, a partir dos depoimentos coletados, que a vivência da enfermidade e dos diferentes estágios do tratamento trazem repercussões psicológicas diversas para as mulheres acometidas de câncer de mama. Cada estágio pôde ser caracterizado em termos dos desafios e tarefas que são exigidos das pacientes, as vivências emocionais associadas, bem como as queixas e os sentimentos emergentes.

Esses achados indicam que o impacto emocional deve ser levado em consideração no planejamento e na implementação de programas de intervenção com essas pacientes, visando a incrementar as possibilidades de ajustamento socioemocional.

\section{Considerações Finais}

Os resultados revelam que as repercussões psicológicas do câncer de mama e de seu tratamento variam conforme o momento vivenciado, dentro do contínuo que se estende desde o diagnóstico até o tratamento. Acompanhando o processo do adoecer, foram identificados quatro momentos distintos, a saber: momento pré-diagnóstico, etapa do diagnóstico, etapa do tratamento emomento pós-tratamento.

No momento pré-diagnóstico, evidencia-se o descuido das pacientes com relação ao próprio corpo, a postergação da consulta médica e a negação da realidade que só seria desvelada com o diagnóstico posteriormente.

Naetapa do diagnóstico, as pacientes formulam suasqueixas quanto à postura negligente dos profissionais médicos e enfatizam os sentimentos vivenciados com relação à doença e ao tratamento: impacto inicial (reação de choque), vislumbre da morte, temores relacionados ao possível desamparo dos filhos, dentre outros.

Na etapa do tratamento, as queixas das pacientes compreendem os efeitos físicos e os danos causados ao organismo pelo tratamento cirúrgico, rádio e quimioterápico, bem como os sentimentos com relação a alterações da imagem corporal.

No momento pós-tratamento, aparecem as repercussões no plano afetivo-sexual e também as dificuldades de adaptação à nova situação de vida, com limitações físicas e restrições, embora também sejam reconhecidas as mudanças positivas trazidas pela experiência de terem passado pelo câncer de mama e seu tratamento.

Os resultados sugerem que as medidas preventivas contra o câncer de mama são insuficientes para a real conscientização da população acerca dos fatores de risco associados à sua etiologia. Parece haver outros componentes, além do cognitivo, envolvidos na decisão da mulher pelo cuidado com o próprio corpo e também pela procura do profissional médico no momento em que começam a ser percebidos os primeiros sinais de alterações nas mamas.

Os resultados evidenciam ainda que as pacientes se percebem vítimas de negligências no decorrer do 
atendimento médico. Isso nos permite inferir as dificuldades dos profissionais médicos no que tange à medicina preventiva, o que pode estar associado à falta de preparo profissional em um campo de alta complexidade, além da indisponibilidade de recursos diagnósticos mais eficazes na identificação de neoplasias em desenvolvimento.

No que diz respeito ao relacionamento médico-paciente, os resultados revelam que o acolhimento e a empatia por parte dos profissionais médicos parecem constituir requisitos fundamentais para que as pacientes se sintam seguras e satisfeitas com a comunicação do diagnóstico. Parece existir uma relação importante entre a qualidade do relacionamento médico-paciente e a aderência ao tratamento, tendo em vista a reabilitação.
Apesar dos efeitos devastadores produzidos pelo adoecimento e pelo tratamento, observa-se nessas mulheres uma expectativa otimista com relação ao futuro. Nota-se que estão "cheias de vida" e esperança, e que reagem à adversidade mais com sentimentos de luta $\mathrm{e}$ enfrentamento do que com uma "entrega resignada" à situação-limite imposta pela doença. Essa postura parecenos essencial na construção de estratégias de enfrentamento mais eficazes diante da situação de adoecimento e tratamento.

Os dados disponíveis fornecem subsídios para o planejamento de uma intervenção mais condizente com as necessidades psicológicas apresentadas pelas pacientes em cada fase do adoecimento e do tratamento.
Leandra Rossi

R. Carlos Chagas, 349, Jardim Paulista, Ribeirão Preto, São Paulo, Brasil. CEP: 14090-190, tel: (Oxx) 16-91298516,E-mail:leandrarossi@ig.com.br

Manoel Antônio dos Santos

R. Cerqueira César, 974, ap. 91, Centro, Ribeirão Preto, São Paulo, Brasil. CEP: 14010-130, tel. (Oxx) 16-602 3645,E-mail:masantos@ffclrp.usp.br
GIMENES, M. daG. G. Alnfluência de Fatores Psicossociais na Sobrevida do Câncer de Mama. Projeto apresentado e aprovado pelo CNPq, processo 405502/88, 1988

GIMENES, M. daG. G. Definição, Foco de Estudoe Intervenção. In: Carvalho, M. M. M. L. (Org.) Introdução à Psiconcologia. Campinas: Editorial Psy, 1994, pp. 35-56.

GIMENES, M. daG. G. eQUEIROZ, E. As DiferentesFases de Enfrentamento Durante o Primeiro Ano Após a Mastectomia. In: Gimenes, M. da G. G. (Org.)Amulhere o câncer. Campinas: Editorial Psy, 1997, pp. 173-195.

KÜBLER-ROSS, E. Sobre a Mortee o Morrer: o que os Doentes Terminais Têm para Ensinar a Médicos, Enfermeiras, Religiosos e aos seus Próprios Parentes. Trad. Paulo Menezes. São Paulo: Martins Fontes, 1994.

LIMA, R. G. O Processo de Trabalho da Enfermagem na Assistência à Criança com Câncer: Análise das Transformações em um Hospital-Escola. Ribeirão Preto. Dissertação de Mestrado. Escola de Enfermagem de Ribeirão Preto, Universidade de São Paulo, 1990.
MINAYO, M. C. S. O Desafio do Conhecimento: Pesquisa Qualitativa em Saúde. São Paulo- Rio de Janeiro: Hucitec-Abrasco, 1994.

MINISTÉRIO DA SAÚDE/INCA. Controle do Câncer: uma Proposta de Integração Ensino-Serviço. $2^{a}$ ed. rev. atual. Rio de Janeiro: Pro-Onco, 1993.

MINISTÉRIO DA SAÚDE. Instituto Nacional do Câncer. Coordenação Nacional de Controle de Tabagismo-CONTAPP. Falando Sobre Câncere seus Fatores de Risco. Rio de Janeiro, 1996.

PARKES, C. M. Luto: Estudos Sobre a Perda na VidaAdulta. Trad. MariaHelena Franco Bromberg. São Paulo: Summus, 1998.

TRIVIÑOS, A. N. S. Introdução à Pesquisa em Ciências Sociais: a Pesquisa Qualitativa em Educação. São Paulo: Atlas, 1992.

WANDERLEY, K. da S. Aspectos Psicológicos do Câncer de Mama. Em: Carvalho, M. M. M. L. Introdução à Psiconcologia. Campinas: Editorial Psy, 1994, pp. 95-101.
Referências 